\title{
Effects of Ice-Phase Cloud Microphysics in Simulating Wintertime Precipitation
}

\author{
Jinwon Kim \\ Han-Ru Cho \\ Sy-Tzai Soong
}

RECEIVED

SEP 069996

OSTI

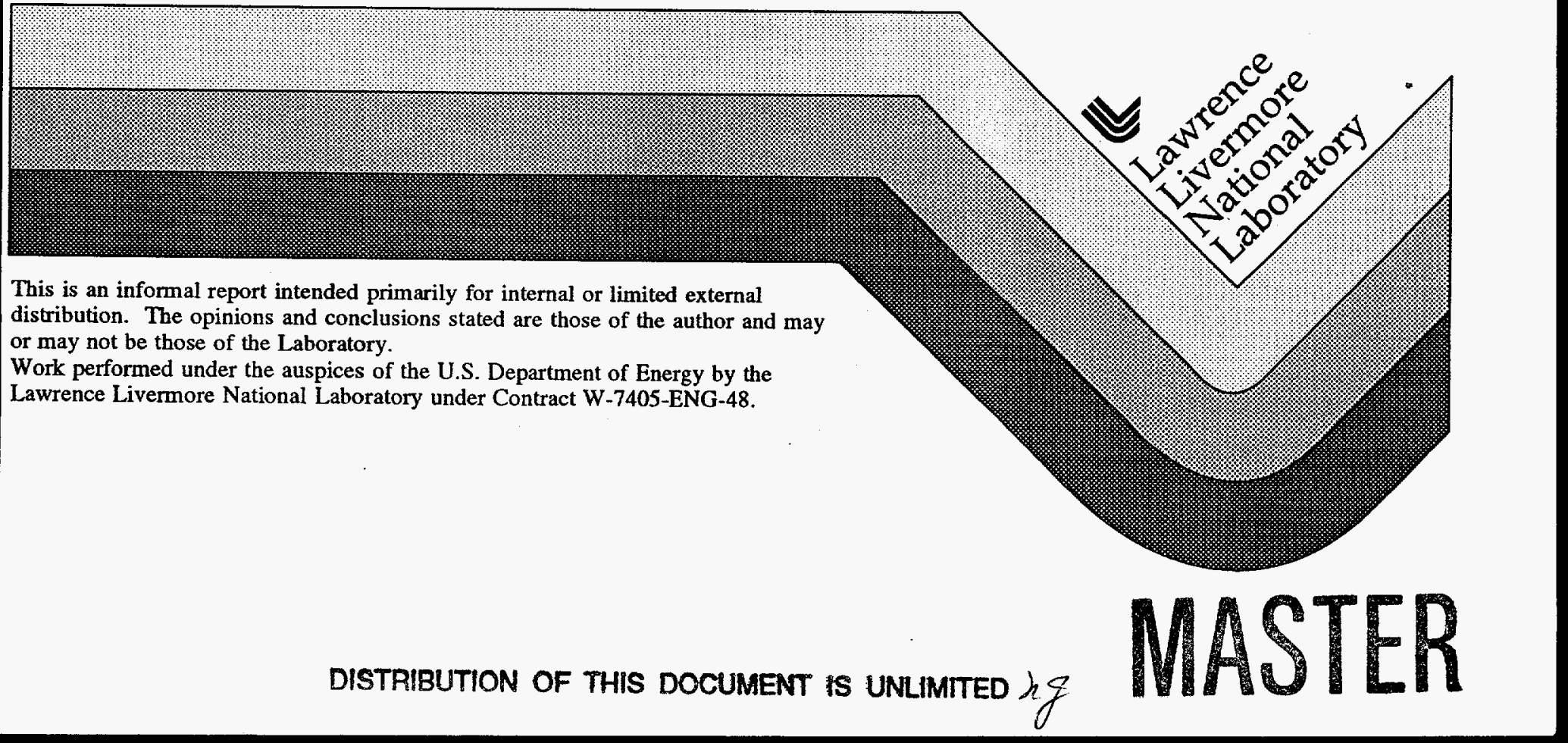




\section{DISCLAIMER}

This document was prepared as an account of work sponsored by an agency of the United States Government. Neither the United States Government nor the University of California nor any of their employees, makes any warranty, express or implied, or assumes any legal liability or responsibility for the accuracy, completeness, or usefulness of any information, apparatus, product, or process disclosed, or represents that its use would not infringe privately owned rights. Reference herein to any specific commercial product, process, or service by trade name, trademark, manufacturer, or otherwise, does not necessarily constitute or imply its endorsement, recommendation, or favoring by the United States Government or the University of California. The views and opinions of authors expressed herein do not necessarily state or reflect those of the United States Government or the University of California, and shall not be used for advertising or product endorsement purposes.

This report has been reproduced

directly from the best available copy.

Available to DOE and DOE contractors from the Office of Scientific and Technical Information

$$
\text { P.O. Box 62, Oak Ridge, TN } 37831
$$

Prices available from (615) 576-8401, FTS 626-8401

Available to the public from the

National Technical Information Service

U.S. Department of Commerce

5285 Port Royal Rd.,

Springfield, VA 22161 


\section{DISCLAIMER}

Portions of this document may be illegible in electronic image products. Images are produced from the best available original document. 
Effects of Ice-Phase Cloud Microphysics in Simulating Wintertime Precipitation

Jinwon Kim

L-262, P.O. Box 808, Lawrence Livermore Nat. Lab., Livermore, CA 94551, U.S.A.

Han-Ru Cho

Dept. of Physics, University of Toronto, Canada

Sy-Tzai Soong

Dept. LAWR, University of California, Davis, CA, U.S.A. 
Effects of Ice-Phase Cloud Microphysics in Simulating Wintertime Precipitation

\author{
Jinwon Kim \\ L-262, P.O. Box 808 LLNL, Livermore, CA 94551 \\ Han-Ru Cho \\ Dept. of Physics, Univ. of Toronto, Canada \\ Su-Tzai Soong \\ Dept. of LAWR, Univ. of California, Davis, CA 95616
}

\begin{abstract}
We compare two numerical experiments to investigate the effects of ice-phase cloud microphysical processes on simulations of wintertime precipitation in the southwestern United States. Results of these simulations, one with and the other without ice-phase microphysics, suggest that an inclusion of ice-phase microphysics plays a crucial role in simulating wintertime precipitation. The simulation that employs both the ice- and water-phase microphysics better reproduced the observed spatial distribution of precipitation compared to the one without ice-phase microphysics. The most significant effect of ice-phase microphysics appeared in local production of precipitating particles by collection processes, rather than in local condensation.
\end{abstract}

\title{
1. Introduction
}

Calculation of the grid-scale condensation and precipitation in mesoscale models is crucial for accurate simulation of local precipitation and storms. Various schemes employed for computing grid-scale precipitation processes frequently cause significant differences in the simulated precipitation and latent heating that result in large variations in the simulated structures of individual storms and local precipitation (Zhang et al., 1988). Recently, bulk microphysics parameterizations (Lin et al. 1983; Rutledge and Hobbs, 1983; Cho et al., 
1989), which usually include two to five classes of hydrometeors have become widely used to compute grid-scale precipitation processes in mesoscale models that do not sufficiently resolve cloud-scale structures (Pielke, 1984). Even though bulk microphysics schemes require more computational resources than isobaric condensation schemes (Haltiner and Williams, 1980), many modelling studies which employed bulk microphysics schemes reported substantial improvements in the simulated precipitation and mesoscale structures of storms (e.g. Giorgi, 1991).

Many earlier studies included only warm rain processes to compute grid-scale condensation. Warm rain processes, which consider two classes of hydrometeors (cloud water and rain), account for most of condensation within low- and mid-level stratiform clouds in middle latitudes, especially during the summertime. Even though an inclusion of warm-rain physics could significantly improve the simulated storm structure and precipitation (Zhang et al. , 1988; Giorgi, 1991), ice-phase processes that include cloud ice, snow, and graupel, are important in precipitation formation associated with winter storms in middle latitudes and with anvil clouds (Dudhia 1989). Amounts of supercooled water rapidly decrease in the temperature range below $263 \mathrm{~K}(-10 \mathrm{C})$ and supercooled water is virtually nonexistent below the temperature of $253 \mathrm{~K}(-20 \mathrm{C})$. Hence, much of mid-and upper level clouds are glaciated during winter seasons in middle and high latitudes.

Ice-phase microphysics affects precipitation through dynamical structures of the simulated storms and through productions of cloud water and cloud ice (hereafter cloud particles) and rain, snow, and graupel (hereafter precipitating particles). Davis et al. (1993) suggested that intensity and development of a simulated storm is closely related to the latent heating. Dudhia (1989) showed that ice-phase processes significantly affects heating profiles in the upper troposphere. Zhang et al. (1989) also showed the importance of ice-phase processes in simulating grid-scale condensation and mesoscale circulations associated with midlatitude 
squall lines.

Cloud particles, in general, do not directly contribute to local precipitation due to their small fall speed. Instead, local concentration of cloud particles affects the rate at which cloud particles are converted into precipitating particles through autoconversion and collection processes. The rate at which cloud particles are produced from water vapor is affected by ice-phase processes mainly due to different saturation vapor pressure over water and over ice. Formation of precipitating particles through autoconversion and collection is also quite different for water- and ice-particles. Hence, ice-phase processes can cause substantial differences in the production of precipitating particles compared to warm-rain processes (Barros, 1994). Enhancement of orographic precipitation by the seeder-feeder mechanism (Rutledge and Hobbs 1983) is much more efficient for snowfall than for rainfall since snow particles sweep more volume of air than raindrops (Choularton and Perry 1986). Previous modeling studies by Cotton et al. (1986) and Burrows (1992) suggested that the seederfeeder mechanism strongly depends on the nucleation rate of ice crystals. A numerical study of Dudhia (1989) also predicted that the production of precipitating particles is enhanced by ice-phase microphysical processes. Different fall speeds of rain and snow particles also affect amounts of precipitating particles transported downstream out of the production area (Rauber 1992), and is an important source of precipitation over lee slopes of major mountain ranges.

In this study, we investigate the effects of ice-phase cloud microphysical processes in simulating wintertime precipitation by comparing the results of two simulations, one includes only warm-rain physics and the other includes both the warm-rain and ice-phase physics. We focus on differences in the simulated productions of cloud- and precipitating particles due to ice-phase processes. 
2. Descriptions of model and experimental conditions

Details of the dynamical and physical formulations of the Mesoscale Atmospheric Simulation (MAS) model were presented by Kim and Soong (1994) and Soong and Kim (1995). Hence we present only a brief outline of the MAS model below:

(1) Governing equations of the MAS model are the flux-form of primitive equation written in $\sigma$-coordinates and discretized on Arakawa c-grid (Mesinger and Arakawa, 1976). Advection of dependent variables except momentum, is computed by a finite difference scheme by Hsu and Arakawa (1990). Advection of momentum is computed using a thirdorder accurate scheme by Takacks (1985). Vertical staggering and differencing of variables follow the formulation by Arakawa and Suarez (1983).

(2) Precipitation processes are computed separately for deep convection and grid-scale condensation using a Kuo-type cumulus parameterization (Kuo, 1965; Krishnamurti et al., 1980) and a bulk cloud microphysics scheme by Cho et al. (1989), respectively. The cumulus parameterization and bulk microphysics scheme are imposed. in the model in such a way that the model atmosphere is adjusted for convection and the adjusted model variables are subjected to microphysical interactions to avoid double counting the total condensation and latent heating. Proper methods of combining a cumulus convection scheme and explicit calculation of microphysical processes in a mesoscale model are still under investigation. In this study, the amount of condensation produced by cumulus scheme was small compared to the amount of condensation produced through microphysics scheme. Hence, this uncertainty in combining cumulus convection scheme with explicit microphysical processes would not affect the results. This lack of condensation due to cumulus convection scheme does not imply that convection was negligible. Soong and Kim (1995) showed that microphysics scheme alone has simulated deep cloud layer over the upslopes of major mountains in this case. 
(3) Solar and terrestrial radiative transfer processes are calculated using multi-layer schemes by Davies (1982) and Harshvardhan and Corsetti (1984), respectively. Details of . these radiation schemes are also presented by Lacis and Hansen (1974) and Harshvardhan et al. (1987). Effects of clouds on the radiative transfer are computed separately for waterand ice-phase cloud particles using the formulations by Stephens (1978) and Starr and Cox (1982), respectively, where amounts and phase of cloud particles are obtained directly from the bulk microphysics scheme.

(4) Surface turbulent fluxes of momentum, heat, and water vapor are computed using the bulk aerodynamic transfer scheme (Deardorff, 1978). Vertical turbulent exchanges above the surface layer are computed using the K-theory. Drag coefficients at the surface and eddy diffusivities above the surface layer, which are dependent on the atmospheric stratification and wind shear, are computed using the formulation by Louis et al. (1981).

(5) Land surface processes are computed using the Coupled-Atmosphere-Plant-Snow (CAPS) model (Mahrt and Pan 1984; Kim et al. 1994; Kim and Ek-1995) that predicts soil water content and soil temperature and diagnoses the temperature and water vapor mixing ratio at land surfaces.

The computational domain covers a $1140 \mathrm{~km} \times 1260 \mathrm{~km}$ wide region that contains the states of California, Nevada, and southern Oregon (Fig. 1). This area is covered with a $20 \mathrm{~km} \times 20$ $\mathrm{km}$ grid mesh in the horizontal. The MAS model was configured with 14 irregularly-spaced layers between the ground surface and the $50 \mathrm{mb}$ level where the top of the computational domain was located (Fig. 2). The top of the computational domain was determined according to the availability of the NMC global analysis data to avoid extrapolating variables in the upper atmosphere. Enhanced horizontal and vertical diffusion was employed within the top 
three layers to reduce wave reflections at the rigid upper boundary. Additional five model layers are introduced between $50 \mathrm{mb}$ and $1 \mathrm{mb}$ levels to compute radiative transfer above the main computational domain.

The atmospheric variables were initialized by interpolating the $2.5^{\circ} \times 2.5^{\circ}$ resolution NMC global analysis data at OOUTC February 111986 using the Cressman objective analysis scheme (Cressman 1959). Time-dependent lateral boundary conditions during the next 12 days were obtained by linearly interpolating the NMC global analysis at 12-hour intervals. The soil texture and initial soil water content were obtained from $1^{\circ} \times 1^{\circ}$ resolution soil texture data and February soil moisture climatology by Zobler (1986).

To investigate the role of ice-phase processes on the simulated precipitation, we carried out two 12-day simulations: Full Microphysics Simulation (FMS) and Warm Rain Simulation (WRS). To compute grid-scale precipitation, FMS employs both warm-rain and ice-phase physics while WRS includes only warm-rain physics. Except the microphysical processes, FMS and WRS share the same experimental conditions with each other.

\section{Simulated precipitation}

Verification of FMS results was presented in detail by Kim and Soong (1994) and Soong and Kim (1995) and will not be repeated here. Instead, we use the observed precipitation to discuss the effects of ice-phase processes on the simulated precipitation. In Figs. 3-5, we present precipitation in inches to compare the simulated values against the analysis by the California Department of Water Resources (1988).

Inclusion of ice-phase processes primarily affected the spatial distribution of precipitation. FMS (Fig. 4) closely reproduced the spatial distribution of the observed precipitation (Fig. 
3) in California during the 12-day period. The location and magnitude of the simulated maximum precipitation of 45.2 inches at the western slope of the northern Sierra Nevada Mountains compares well with the observed value of 49.6 inches at similar location. When we removed ice-phase processes (Fig. 5), two major changes occurred in the spatial distribution of the simulated precipitation: (1) precipitation over the Coastal Range and the Central valley is significantly reduced, and (2) the simulated precipitation is confined within much narrower areas, mostly over the western slopes of the Coastal Range and the Sierra Nevada. In addition, WRS overestimated the maximum precipitation along the western slope of the Sierra Nevada Mountains by as much as 12 inches.

Quantitative investigation of effects of ice-phase processes in the spatial distribution of the simulated precipitation is performed by comparing grid-point values with raingauge values in three regions within California: the Coastal Range, the Central Valley, and the Sierra Nevada. The number of grid points included in computing the average precipitation within individual regions is presented in Table 1.

Comparison of the observed and simulated regional-mean precipitation (Fig. 6) clearly shows the spatial bias caused by the absence of ice-phase processes. While FMS closely reproduced the observed precipitation within all three regions, WRS substantially underestimated the observed precipitation within the Coastal Range and the Central Valley regions, by more than $50 \%$ of the observed values. WRS closely simulated the observed precipitation within the Sierra Nevada region. It is misleading, however, since general overestimation of precipitation intensity by WRS within the Sierra Nevada region was partially compensated by narrower spatial coverage of WRS precipitation. When averaged over entire California area, which combines the Coastal Range, the Central Valley, and the Sierra Nevada regions, WRS underestimated the observed precipitation by approximately $20 \%$. 
Figs. $7 \mathrm{a}$ and $\mathrm{b}$ compare the 12-day total grid-point precipitation from FMS and WRS against the 12-day total raingauge-observed value. Both FMS (Fig. 7a) and WRS (Fig. 7b) produced similar correlation coefficients between raingauge and grid-point values with 0.87 for FMS and 0.83 for WRS, respectively. However, Fig. 7 clearly shows that WRS underestimated (overestimated) the observed values within the range where the simulated precipitation is less (more) than $40 \mathrm{~cm}$ while FMS precipitation does not show such systematic error. This bias in WRS precipitation is a consequence of incorrect spatial distribution of simulated precipitation as discussed above.

Effects of the ice-phase cloud microphysics on the simulated precipitation discussed in the above were consistent throughout the simulation period. The simulated daily precipitation within entire California and individual regions was affected by the absence of the ice-phase microphysics in a similar way as the 12-day total values. The daily precipitation over the Coastal Range and Central Valley was generally less than $50 \%$ of the FMS daily precipitation throughout the 12-day period while the daily precipitation over the Sierra Nevada in WRS is about the same as that from FMS (Fig. 8).

4. Cloud and precipitation particle productions

This section discusses effects of ice-phase processes on the simulated productions of cloudand precipitating particles over a 12-hour period, 00-12UTC, February 15. Investigations of other parts of the simulation period yielded similar results.

Distributions of total amounts of locally produced cloud- and precipitating particles (Figs. 9 and 10) were computed by integrating the instantaneous production rates vertically and over the 12-hour period as 


$$
P_{i, j}^{\ell}=\sum_{n=1}^{N} \delta_{\ell}\left[\sum_{k=1}^{K} \delta p_{k} \hat{S}_{i, j, k}^{\ell} / g\right]_{n}
$$

where $P_{i, j}^{\ell}$ is total production of a species $\ell$ (cloud- or precipitating particles) at a grid $(i, j), g$ is the gravitational acceleration, $\delta p_{k}$ is the pressure-thickness of a grid box at $(i, j, k), \hat{S}_{i, j, k}^{\ell}$ is the instantaneous production rate of a species $\ell$ within a grid box, $\delta_{t}$ is the time-step increment, $K$ is number of layers, and $N$ is number of time steps. Sink terms, such as reduction of cloud particles due to the conversion into precipitating particles or removal of precipitating particles at the surface, were not included in calculating total productions. Hence, local productions of cloud- and precipitating particles in the following imply total condensation and total conversion of cloud particles into precipitating particles at a given location, respectively.

Local production of cloud particles in FMS (Fig. 9a) and in WRS (Fig. 9b) are similar to each other. In both WRS and FMS, cloud particles were produced mostly over the western slopes of the Coastal Range and the Sierra Nevada. Production of cloud particle in WRS occurred in somewhat narrower area than in FMS. However, this difference is small. WRS predicted somewhat larger values at local maxima, especially at the northern and southern Sierra Nevada where WRS generated more condensation than FMS by as much as $10 \mathrm{~kg} \mathrm{~m}^{-2}$ over the 12-hour period.

Ice-phase microphysical processes significantly affected the production of precipitating particles (Figs. 10a and b) as suggested by previous studies (Choularton and Perry, 1986; Dudhia, 1989). Compared to WRS, FMS (Fig. 10a) produced precipitation over wider areas, extending to the upstream sides of the western slopes of the Coastal Range and the Sierra Nevada, over the Pacific Ocean and over the Central Valley. On the contrary, WRS produced precipitating particles within narrow areas over the western slopes of the Coastal Range and 
the Sierra Nevada (Fig. 10b). Compared to FMS, WRS produced much less precipitating particles over the Coastal Range and the Central Valley. Over the Sierra Nevada, WRS produced more precipitating particles than FMS by $20 \mathrm{~kg} \mathrm{~m}^{-2}$. This local production of precipitating particles closely resembles the simulated surface precipitation in FMS and WRS (Figs. 4 and 5).

Local production of precipitating particles is further complicated by combined effects of the efficiency for converting cloud particles into precipitating particles and the downstream advection of cloud particles. Fig. 11 illustrates the conversion efficiency along the dashed line shown in Fig. 1. The conversion efficiency is defined as the ratio of the local production of precipitating particles to the local production of cloud particles. Therefore, it can exceed unity in the presence of horizontal advection of cloud particles. In FMS, a large portion of locally produced cloud particles were converted into precipitation, especially over the Coastal Range and the Sierra Nevada where the conversion efficiency was near $100 \%$. The conversion efficiency over the Central Valley was about $70 \%$, somewhat lower than that within the major production areas probably due to small cloud particle concentration. The conversion efficiency in WRS was generally lower than that in FMS except over the Sierra Nevada. As a result, WRS underestimated precipitation within the Coastal Range and the Central Valley regions even though it produced similar amount of local condensation as FMS. In WRS, a large portion of cloud droplets produced within the Coastal Range and the Central Valley regions was transported downstream due to low conversion efficiency within these regions. These additional cloud particles enhanced the precipitation production over the Sierra Nevada.

Cloud particles are converted into precipitation through two processes, autoconversion and collection. Along the same cross-section shown in Fig. 11, autoconversion in FMS was much larger than that in WRS (Fig. 12a). Amounts of precipitation generated through collection 
processes (Fig. 12b) strongly depend on the arrangement of the underlying terrain where FMS yielded more (less) collection than WRS over the Coastal Range (Sierra Nevada). Large amounts of collection in WRS over the Sierra Nevada is a consequence of large amounts of cloud particles advected into the region from the Coastal Range. Within the scope of the microphysics parameterization used in this study, collection of cloud particles by precipitating particles generated more than $80 \%$ of total precipitation.

Quantitative contributions from autoconversion and collection processes to the enhancement of conversion efficiency over the Coastal in FMS are not clear since autoconversion of cloud ice to form snow critically depends on the threshold value. The difference in autoconversion between FMS and WRS (Fig. 12a) was caused mainly by different threshold values used to compute autoconversion where the threshold value for cloud water to form raindrops is $7 \times 10^{-4} \mathrm{~kg} / \mathrm{kg}$ while that for cloud ice to form snow is $2.5 \times 10^{-5} \mathrm{~kg} / \mathrm{kg}$. This threshold value for autoconversion of cloud water to form raindrops was taken directly from Rutledge and Hobbs (1983) and is similar to Lin et al. (1983) where a threshold value of $10^{-3} \mathrm{~kg} / \mathrm{kg}$ was used. Unfortunately, in bulk cloud microphysics schemes we reviewed (Lin et al. 1983; Rutledge and Hobbs 1983; Cho et al. 1989), autoconversion (or transfer) of cloud ice to form snow is highly parameterized with large uncertainties in the threshold values. For example, the value of $2.5 \times 10^{-5} \mathrm{~kg} / \mathrm{kg}$ we used in this study corresponds to the one suggested by Rutledge and Hobbs (1983) at $-25 \mathrm{C}$. On the other hand, Lin et al. (1983) suggested the threshold value of $10^{-3} \mathrm{~kg} / \mathrm{kg}$. To investigate the effects of different threshold values for cloud ice autoconversion, we repeated FMS with a threshold value of $7 \times 10^{-4} \mathrm{~kg} / \mathrm{kg}$, the same value as autoconversion of cloud water. With larger threshold value, autoconversion of cloud ice into snow was substantially reduced over the Coastal Range, even smaller than in WRS (not shown). Despite this reduction in the initiation of snow, precipitation particles produced through collection process remained almost unchanged. Based upon this additional simulation, we conclude that enhanced conversion efficiency in FMS over the Coastal Range 
is mainly caused by enhanced collection of cloud particles in the presence of snow.

Finally, a simulation without graupel processes produced almost same results as FMS (not shown). Therefore, for coarse resolution mesoscale models that can not resolve cloud scale structures, four-species microphysics scheme that include cloud water, cloud ice, rain and snow, may be adequate for simulating grid-scale condensation and precipitation.

\section{Conclusions}

Effects of ice-phase microphysical processes on the simulated wintertime precipitation were investigated. The inclusion of ice-phase processes significantly affected the simulated precipitation in its amount and spatial distribution. The simulation without ice-phase processes caused significant bias in the spatial distribution of the simulated precipitation while the simulation which included both warm-rain and ice-phase processes accurately reproduced the observed precipitation within California. Compared with the simulation which included both warm-rain and ice-phase processes, the simulation without ice-phase processes underestimated precipitation over the Coastal Range and the Central Valley by more than $50 \%$ and substantially overestimated precipitation over the Sierra Nevada.

The major impact of ice-phase processes occurred in the local production of precipitating : particles, rather than in the local production of cloud droplets. When ice-phase processes were removed, the conversion efficiency at which locally-produced cloud particles are converted into precipitating particles was significantly reduced over the Coastal Range and over the Central Valley. In the absence of ice-phase processes, lower conversion efficiency over the Coastal Range caused large amount of cloud particles to be advected into the Sierra Nevada region. This downstream transport of cloud particles in the absence of ice-phase processes significantly enhanced local precipitation over the Sierra Nevada. The difference 
in the conversion efficiency due to the absence/presence of ice-phase processes was caused mainly by the difference between the raindrops and snow particles in collecting cloud particles. For coarse resolution mesoscale models, four-species microphysics scheme may be adequate for simulating grid-scale condensation and precipitation.

\section{Acknowledgment}

The authors thank Dr. John Roads of Scripps Institution of Oceanography for providing the raingauge data over California and for valuable discussions. We also thank William Mork of the California Department of Water Resources for providing an analysis of the observed precipitation as well as valuable discussions. Special thanks for B. Lawver, E. Bush, and E. Davis for their computational support. This work is supported by National Institute for Climate Change (NIGEC) under the grant W/GEC0017, Institutional Collaborative Research (INCoR) Program of Univ. of California, and Laboratory Directed Research and Development (LDRD) Program of Lawrence Livermore Nat. Laboratory. Work performed under the auspices of the U. S. Dept. of Energy by the Lawrence Livermore National Laboratory under contract No. W-7405-Eng-48.

References

Arakawa, A. and M. Suarez, 1983: Vertical differencing of the primitive equations in sigma coordinates., Mon. Wea. Rev., 111, 34-45.

Bader, M. and W. Roach, 1977: Orographic rainfall in warm sectors of depressions. Q. J. Roy. Meteorol. Soc., 103, 269-280.

Barros, A. 1994: Dynamic modeling of orographically induced precipitation. Rev. Geophys., $32, \quad 265-284$.

Burrows, D., 1992: Evaluation of a two-dimensional kinematic cloud model using data from 
a central Sierra Nevada orographic cloud system. J. Clim. Appl. Meteorol., 31, 5163.

California Dept. of Water Resources, 1988: California high water 1985-1986. Dept. of Water Resources Bulletin 69-86, State of California Dept. of Water Resources, Sacramento, California, $107 \mathrm{pp}$.

Cho, H.-R., M. Niewiadomski,J. Iribarne and O. Melo, 1989: A model of the effect of cumulus clouds on the redistribution and transformation of pollutants. J. Geophys. Res., 94, No. D10, $12895-12910$.

Choularton, T. and S. Perry, 1986: A model of the orographic enhancement of snowfall by the seeder-feeder mechanism. Q. J. Roy. Meteorol. Soc., 112, 113-129.

Cotton, W., G. Tripoli, R. Rauber, and E. Mulvihill, 1986: Numerical simulation of the effects of varying ice crystal nucleation rates and aggregation processes on orographic snowfall. J. Clim. Appl. Meteorol., 25, 1658-1680.

Cressman, G., 1959: An operational objective analysis system. Mon. Wea. Rev., 87, 367374.

Davies, R., 1982: Documentation of the solar radiation parameterization in the GLAS climate model., NASA Tech. Memo. 83961, NASA GSFC, Greenbelt, Maryland, 57pp.

Davis, C., M. Stoelinga, and Y. Kuo, 1993: The integrated effect of condensation in numerical simulations of extratropical cyclogenesis. Mon. Wea. Rev., 121, 2309-2330.

Deardorff, J. W., 1978: Efficient prediction of ground surface temperature and moisture, with inclusion of a layer of vegetation., J. Geophys. Res., 83, No. C4, 1889-1903.

Dudhia, J., 1989: Numerical study of convection observed during the Winter Monsoon Experiment using a mesoscale two-dimensional model., J. Atmos. Sci., 46, 30773107.

Dickinson, R., R. Errico, F. Giorgi, and G. Bates, 1989: A regional climate model for western United States., Climate Change, 15, 383-422.

Ek, K. and L. Mahrt, 1991: OSU 1-D PBL Model User's Guide., Dept. of Atmos. Science, 
Oregon State Univ., Corvallis, OR., $118 \mathrm{pp}$.

Ellingson, R. G., J. Ellis, and S. Fels, 1991: The inter-comparison of radiation codes used in climate models: Long wave results., J. Geophys. Res., 96, No. D5, 8929-8953.

Frisch, J. and C. Chappel, 1980: Numerical prediction of convectively driven mesoscale pressure systems. Part i: Convective parameterization., J. Atmos. Sci., 37, 17221733

Giorgi, F., 1991: Sensitivity of simulated summertime precipitation over the western United States to different physics parameterizations., Mon. Wea. Rev., 119, 28702888 .

Gocho, Y., 1978: Numerical experiment of orographic heavy rainfall due to stratiform cloud. J. Meteorol. Soc. Japan, 56, 405-422.

Harshvardahn and T. Corsetti, 1984: Longwave radiation parameterization for the UCLAVGLAS GCM., NASA Tech. Memo. 86072. NASA GSFC, Greenbelt, Maryland, 33pp.

Hsu, Y. and A. Arakawa, 1990: Numerical modeling of the atmosphere with an isentropic vertical coordinate. Mon. Wea. Rev., 118, 1933-1959.

Kim, J. and S.-T. Soong, 1994: Simulation of a precipitation event in the western United States., Proceed. Sixth Conf. on Climate Variations, Jan. 1994; Nashville, TN, 403406.

Kim, J., M. Ek, and R. Lee, 1994: A long-term simulation of surface fluxes and soil moisture., Proceed. Sixth Conf. on Climate Variations, Jan. 1994, Nashville, TN, $407-410$

Lin, Y., R., Farley, and H. Orville, 1983: Bulk parameterization of the snow field in a cloud model., J. Climate and Appl. Met., 22, 1065-1092.

Louis, J. F., M. Tiedke, and J. Geleyn, 1981: A short history of the operational PBLparameterization at ECMWF., Workshop on planetary boundary parameterization., 59-79, ECMWF, 260pp.

Mahrt, L. and H.-L. Pan, 1984: A two-layer model of soil hydrology., Bound.-Layer Met., 
$29,1-20$.

Mesinger F. and A. Arakawa, 1976: Numerical methods used in Atmospheric models. GARP Publ. Series 17, Global Atm. Res. Prog., WMO.

Pielke, R. A., 1984, Mesoscale Meteorological Modeling. Academic Press, London, United Kingdom, $612 \mathrm{pp}$.

Rauber, R., 1992: Microphysical structure evolution of a central Sierra Nevada orographic cloud system. J. Appl. Meteorol., 31, 3-24.

Rutledge, S. and P. Hobbs, 1983: The mesoscale and microscale structure and organization of clouds and precipitation in midlatitude cyclones, VIII: A model for the "seeder-feeder" process in warm-frontal rainbands. J. Atmos. Sci., 40, 1185-1206.

Soong, S.-T. and J. Kim, 1995: Simulation of a heavy wintertime precipitation event in California. Climatic Change, in press.

Starr, D. and S. Cox, 1985: Cirrus clouds. Part I: A cirrus cloud model., J. Atmos. Sci., 42, $2663-2681$.

Stephens, G., 1978: Radiation profiles in extended water clouds. 11: Parameterization schemes., J. Atmos. Sci., 35, 2123-2132.

Storebo, P., 1976: Small scale topographical influences on precipitation. Tellus, 28, 4559.

Takacs, L. L., 1985: A two-step scheme for the advection equation with minimized dissipation and dispersion errors. Mon. Wea. Rev., 113, 1050-1065.

Zhang, D.-L., E.-Y. Hsie, and M. Moncrieff, 1988: A comparison of explicit and implicit predictions of convective and stratiform precipitating weather systems with a meso$\beta$-scale numerical model., Q. J. Roy. Met. Soc., 114, 31-60.

Zhang, D.-L., K. Gao, and D. Parson, 1989: Numerical simulation of an intense squall line during 10 - 11 June 1985 Pre-Storm. Part l: Model verification., Mon. Wea., Rev., 117, $960-994$.

Zobler, L., 1986: A world soil file for global climate modeling., NASA Tech. Memo. \#87802. 
List of Tables

Table 1. The number of grid points containing at least one raingauge station within the entire California and individual subregions

Regions

Number of grid points

California

161

Coastal Range

63

Central Valley

31

Sierra Nevada

67 
Figure Legends

Fig. 1 Model orography represented at $20 \mathrm{~km} \times 20 \mathrm{~km}$ resolution.

Fig. 2 Vertical structure of the coupled MAS-CAPS model used in this study.

Fig. 3 The observed twelve-day total precipitation in inches in California.

Fig. 4 The simulated twelve-day total precipitation in inches from the FMS.

Fig. 5 Same as Fig. 4, but from the WRS.

Fig. 6 Twelve-day total precipitation over the Coastal Range, the Central Valley, the Sierra Nevada, and the entire California from the rainguage data, FMS, and WRS.

Fig. 7 Twelve-day total precipitation observed at individual rainguage stations (ordinate) and simulated at station-containing grid points (abscissa) from FMS (a) and WRS (b).

Fig. 8 The simulated daily-mean precipitation over individual regions from FMS and WRS.

Fig. 9 The simulated vertically-integrated production of cloud particles over a 12-hour period (00-12UTC, Feb. 1986) along the dashed line in Fig. 3: (a) FMS and (b) WRS.

Fig. 10 Samie as Fig. 9 except for vertically-integrated production of precipitating particles: (a) FMS and (b) WRS.

Fig. 11 The conversion efficiency simulated in the FMS (heavy solid curve) and the WRS (dashed curve). The thin horizontal line indicates $100 \%$ conversion efficiency. The heavy solid line at the bottom of the figure represents the terrain along.the crosssection. One grid interval corresponds to $20 \mathrm{~km}$. The period and corss-section are the : same as in Fig. 9.

Fig. 12 Precipitation production by (a) Autoconversion (b) Collection. The period and corss-section are the same as in Fig. 9. 


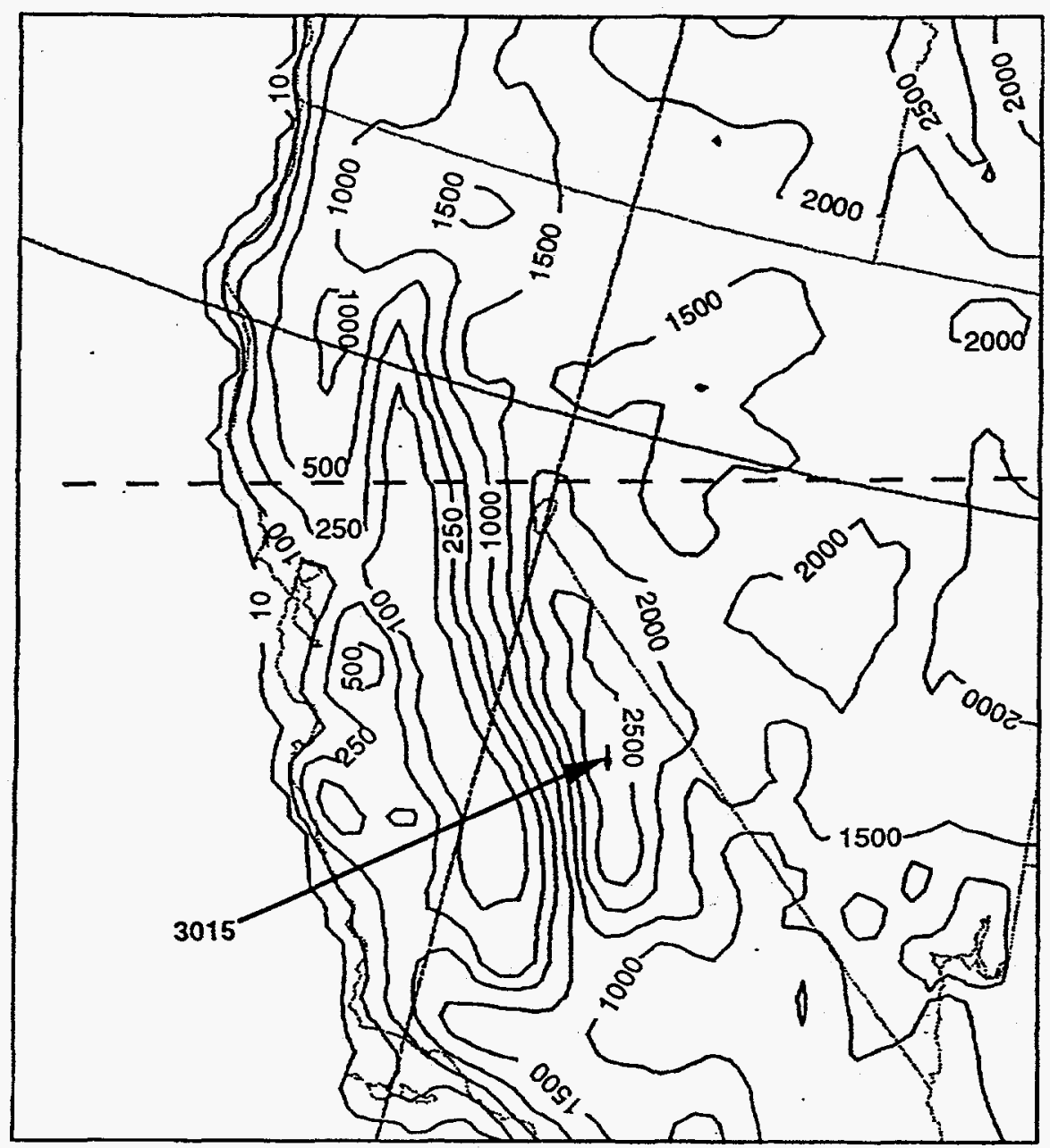

Fig. 1 
$1 \mathrm{mb}$

5 Radiation Layers

$50 \mathrm{mb}$

$\sigma=0$

14 Atmospheric Layers

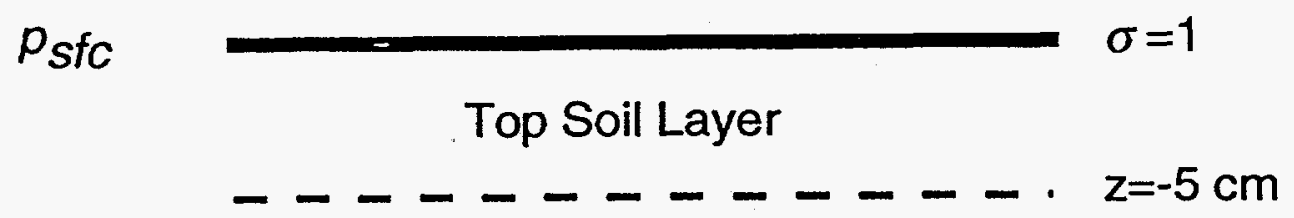

Bottom Soil Layer

$\Pi 777777777$ z=-3 m

Deep Soil Layer 


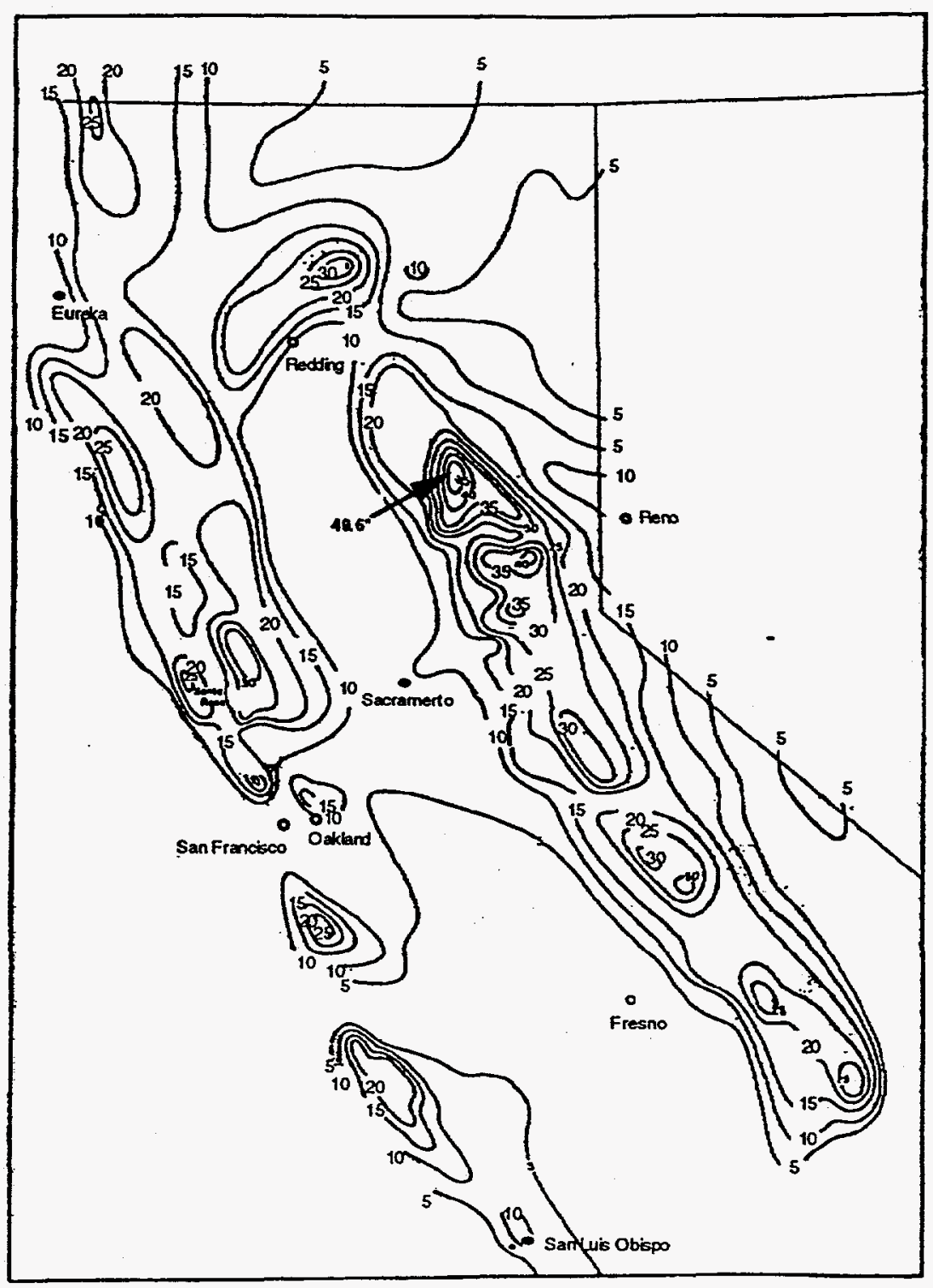

Fig. 3 


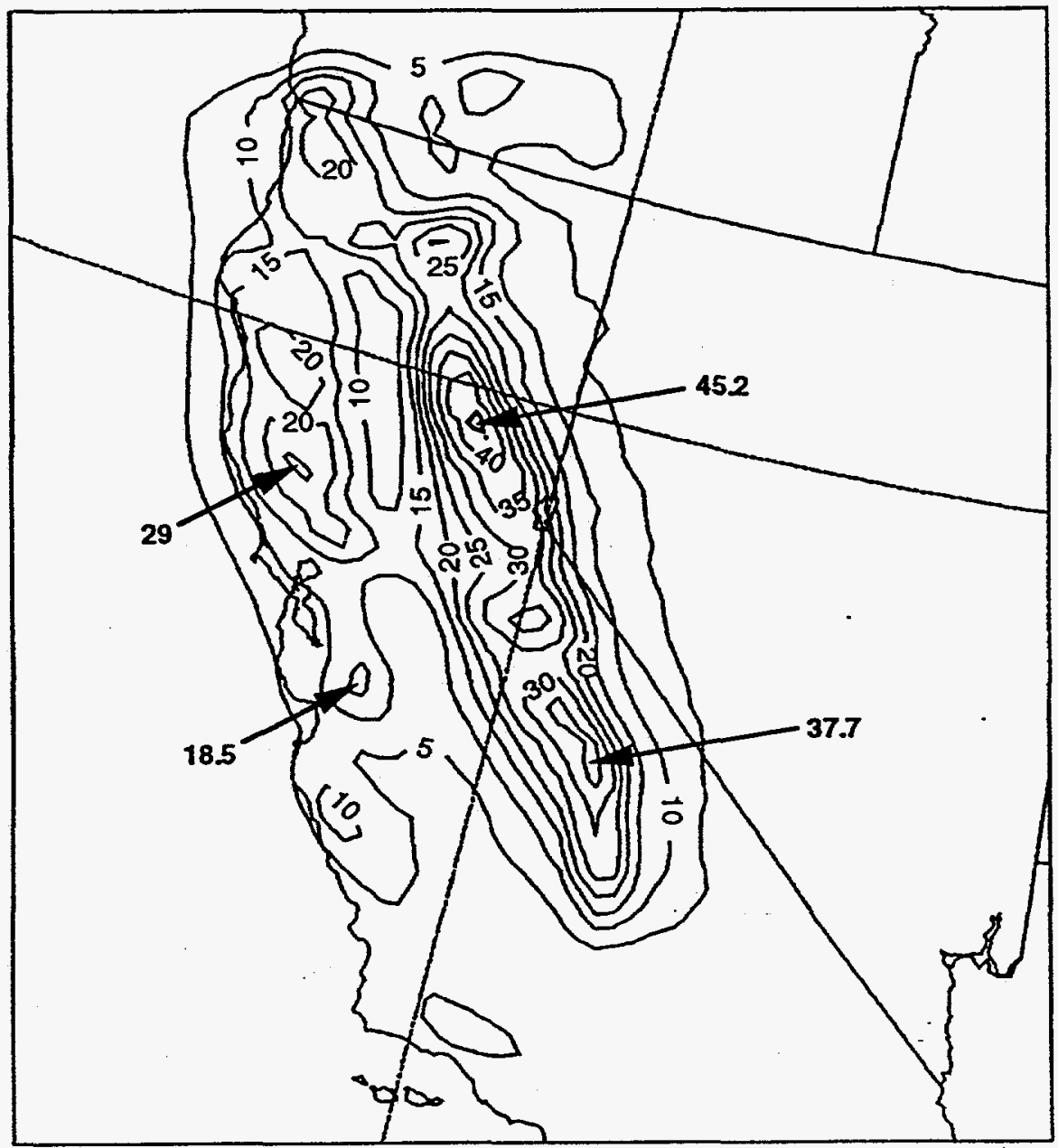

Fig. 4 


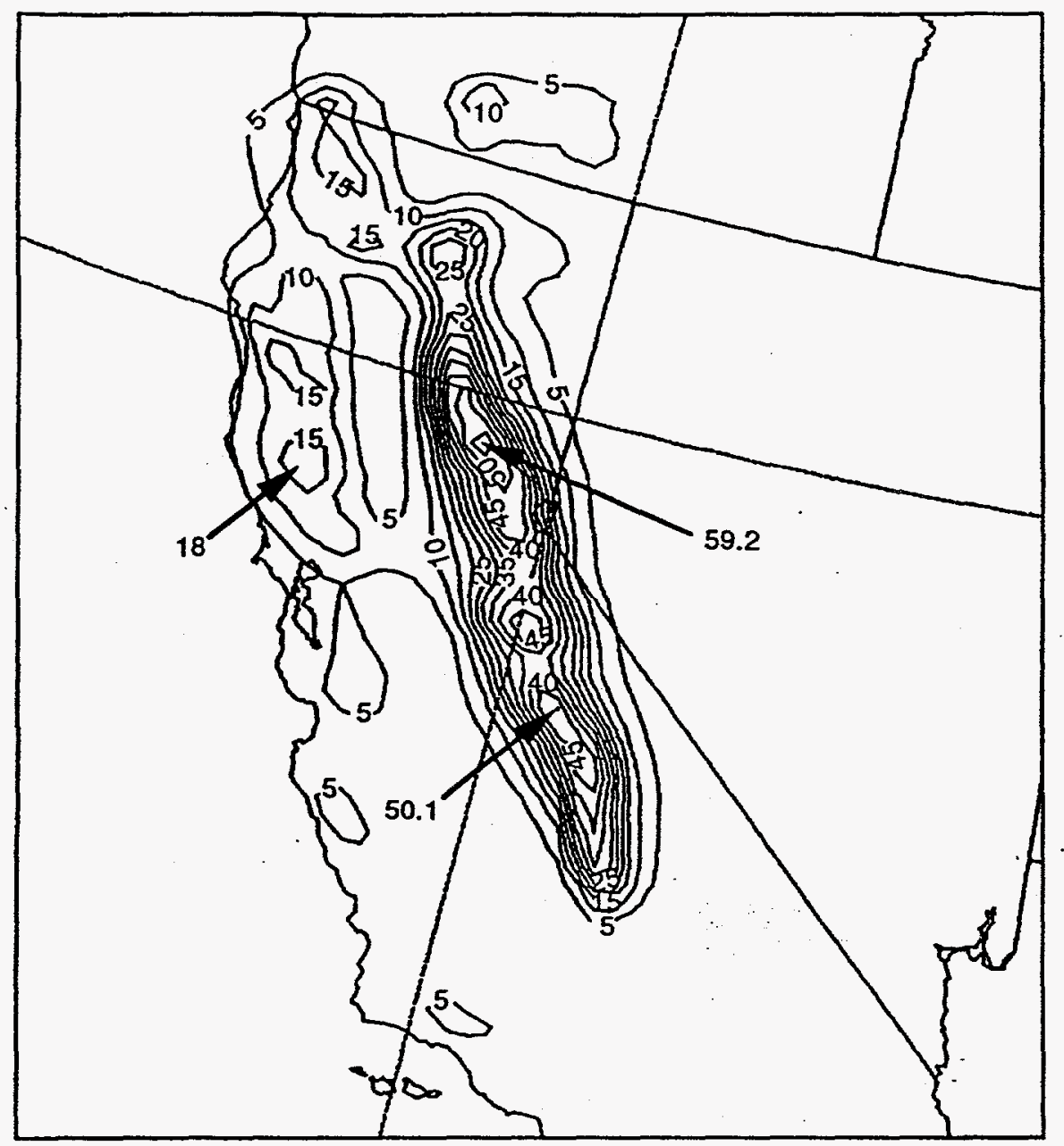

Fig. 5 


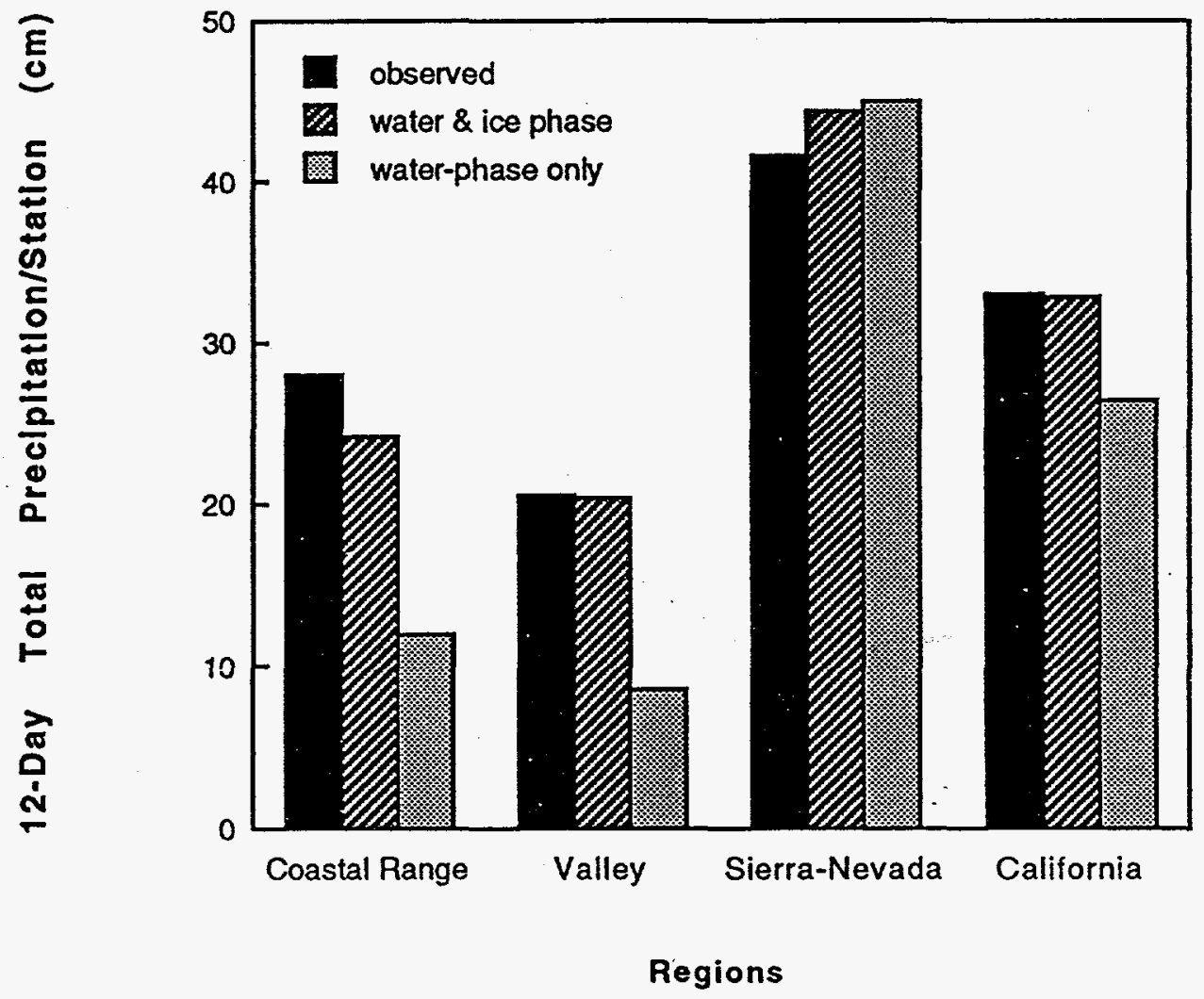

Fig. 6 

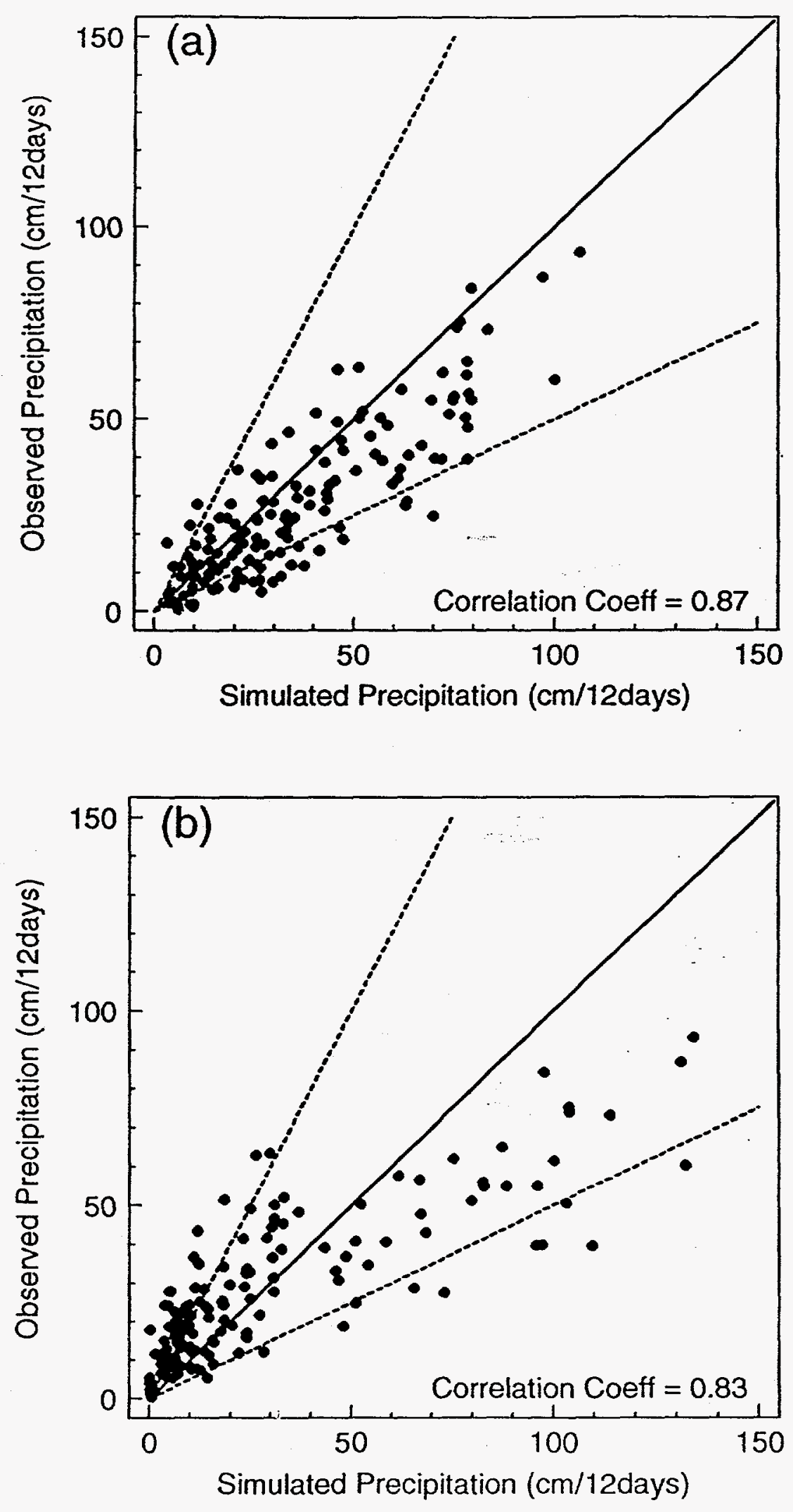

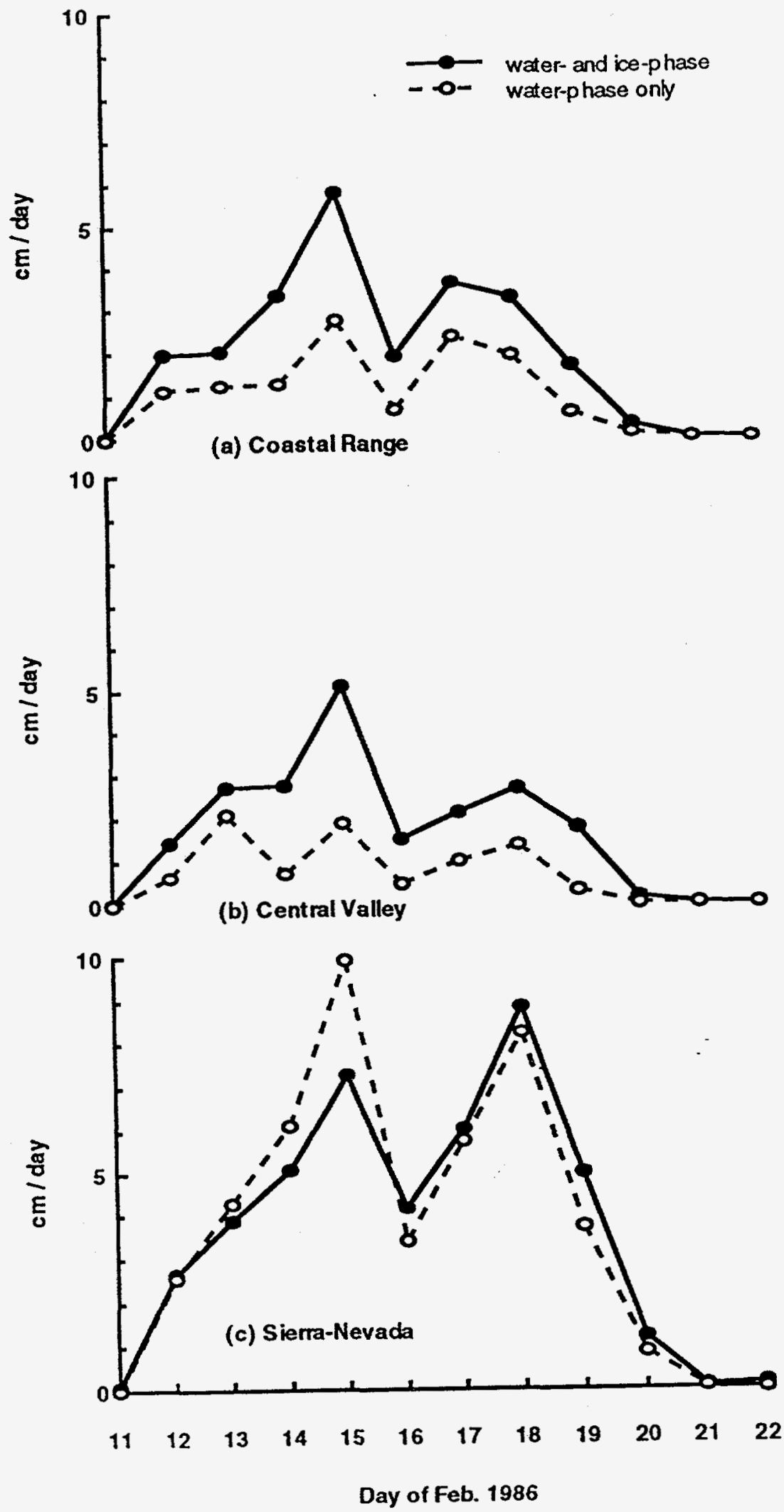

Fig. 8 


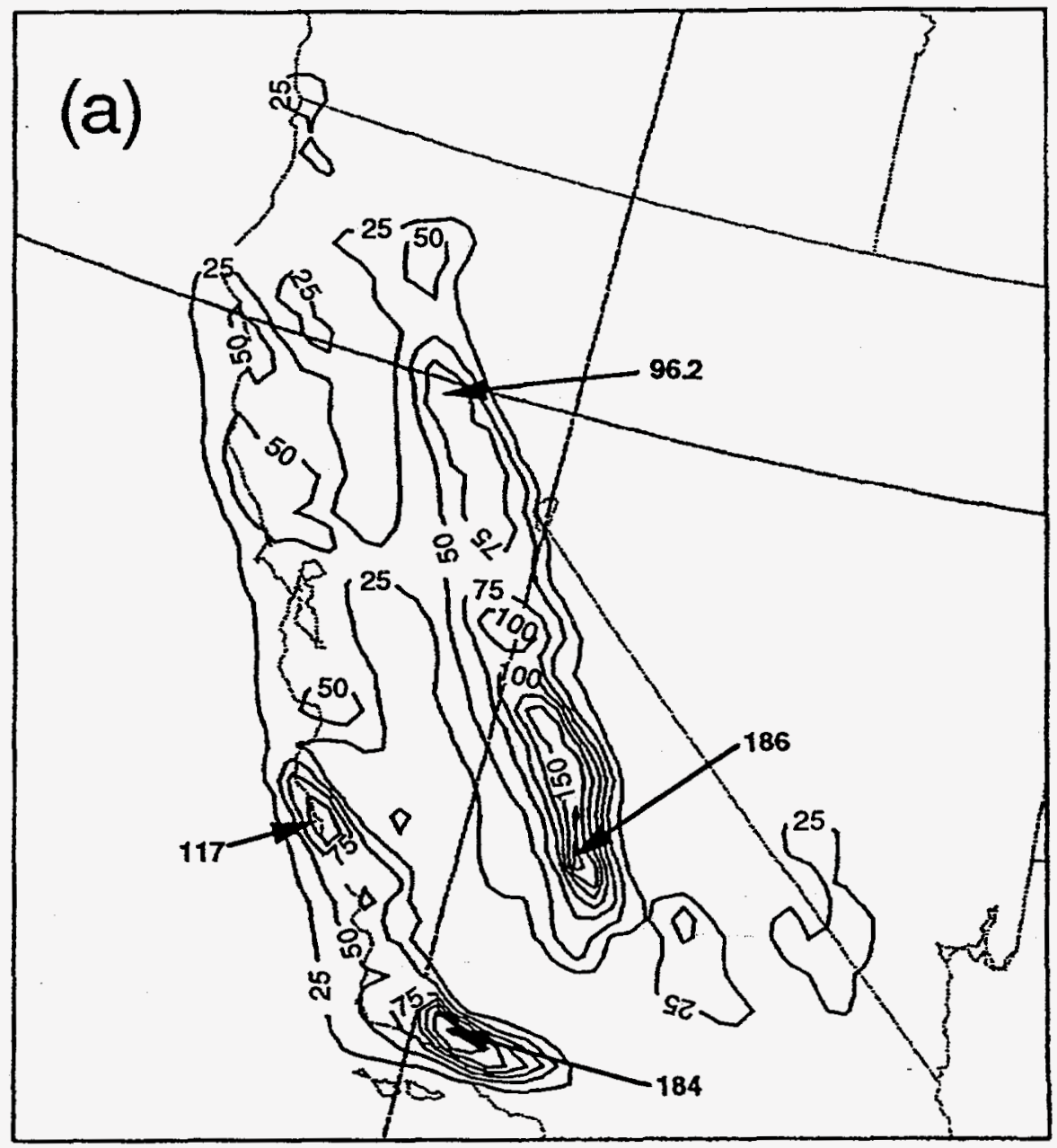

Fig. 9a 


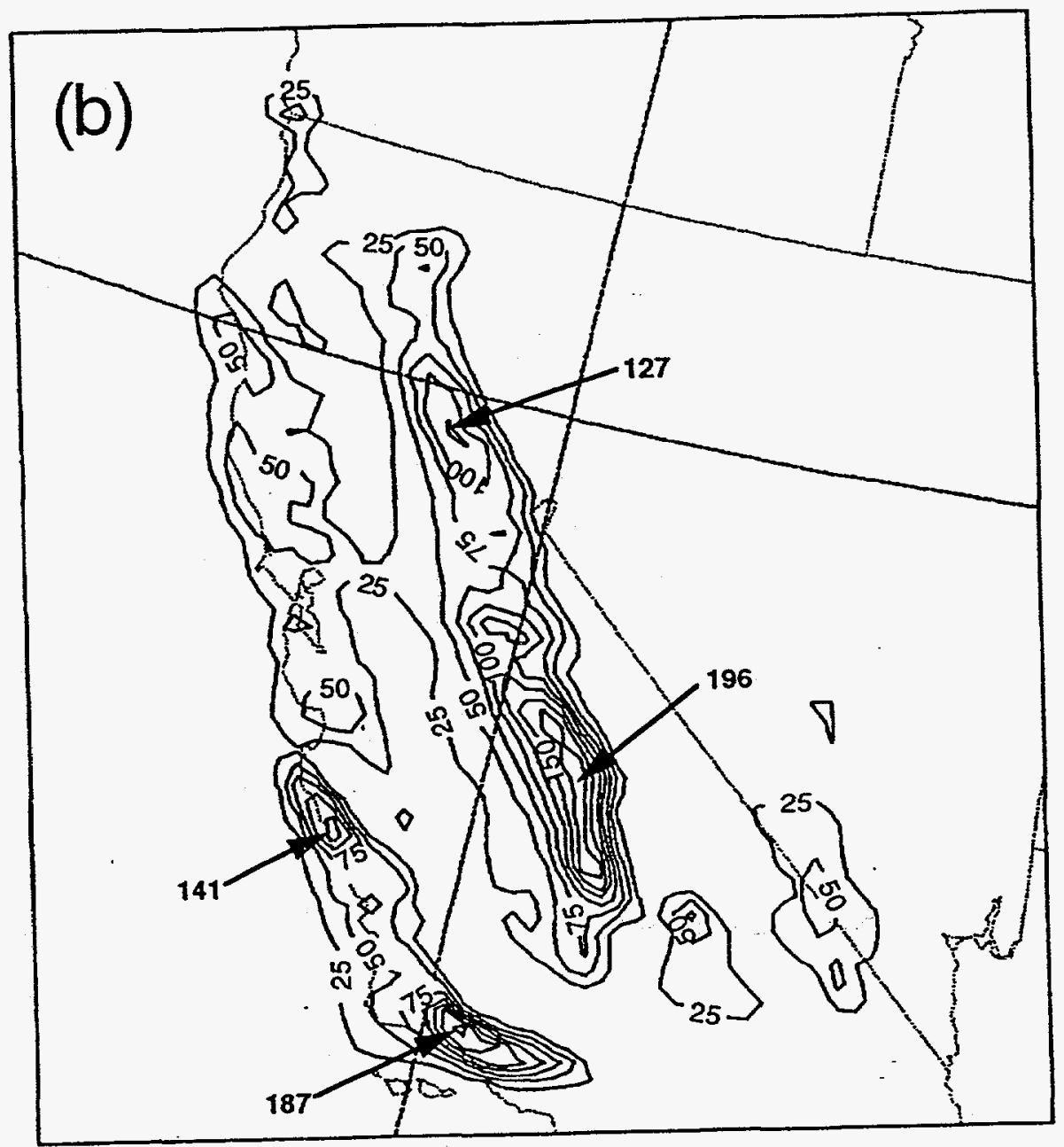

Fig. 9b 


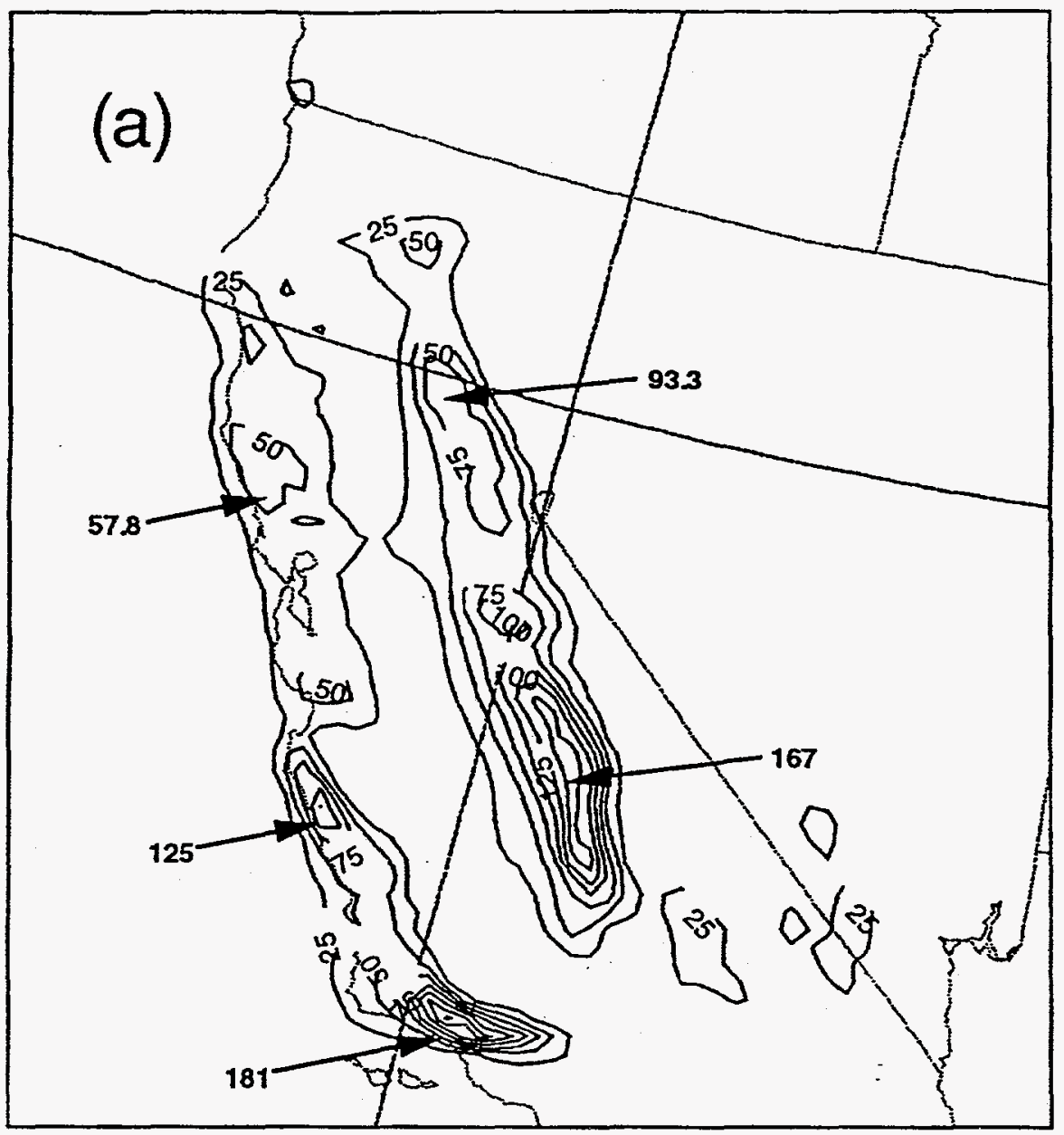

Fig, $10 a$ 


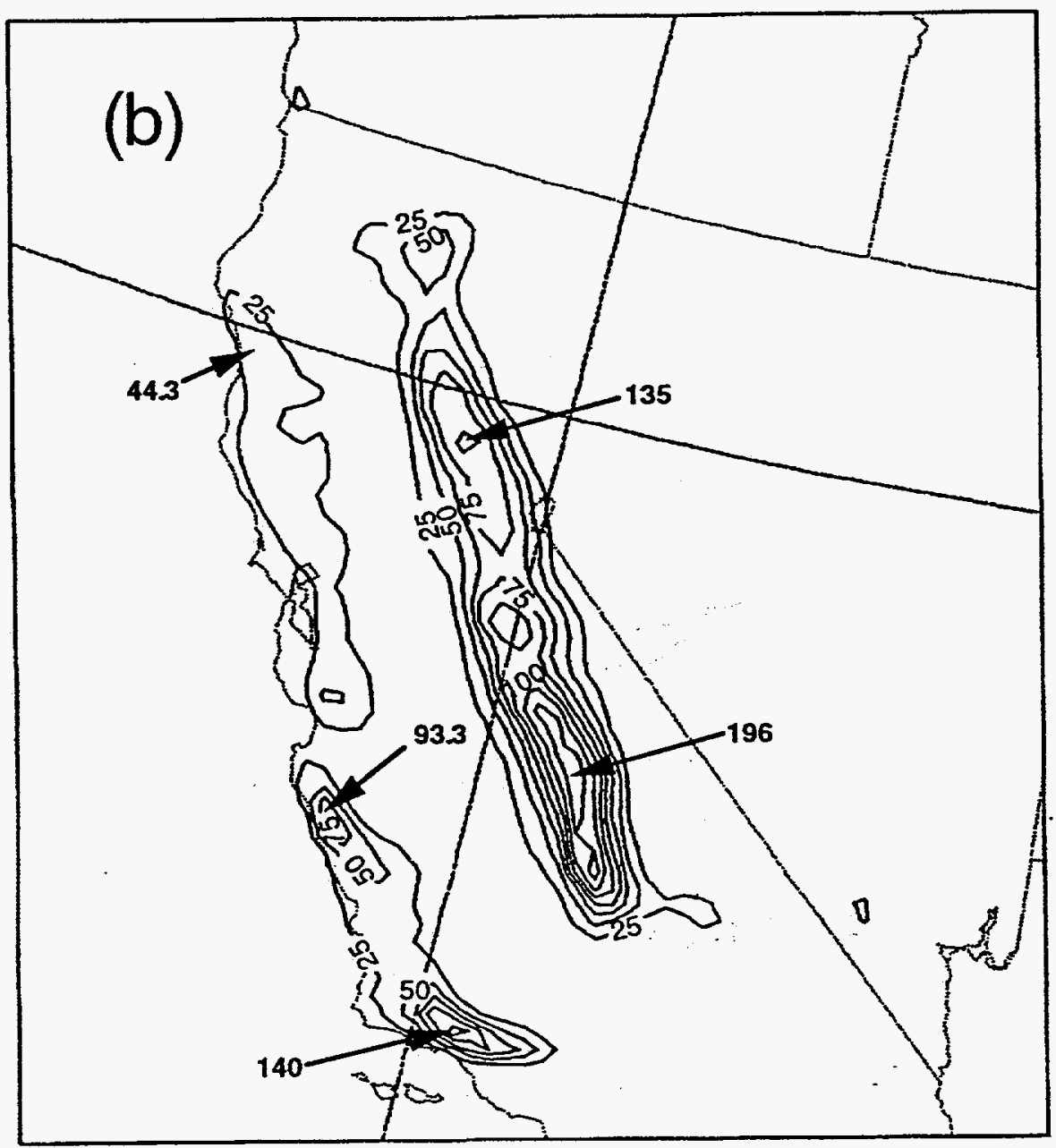

Fig. 10b 


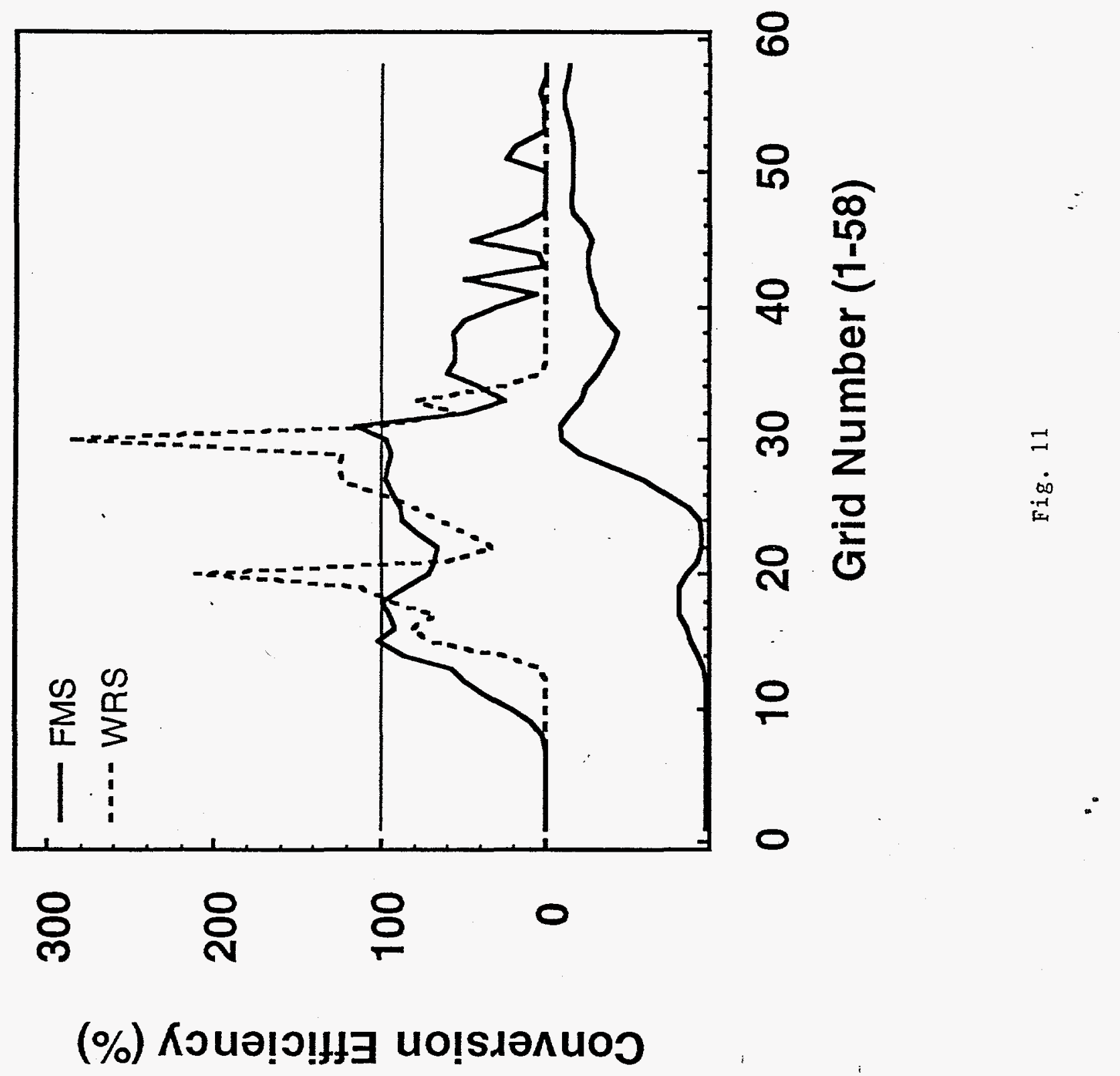




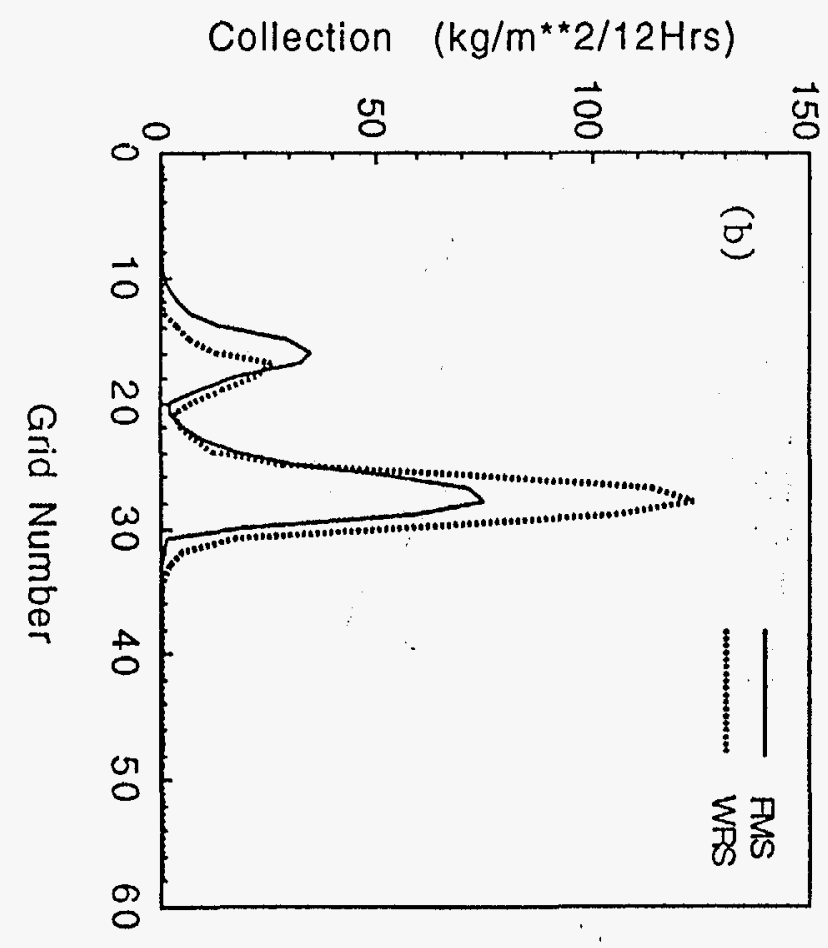

Autoconversion (kg/m**2/12Hrs)

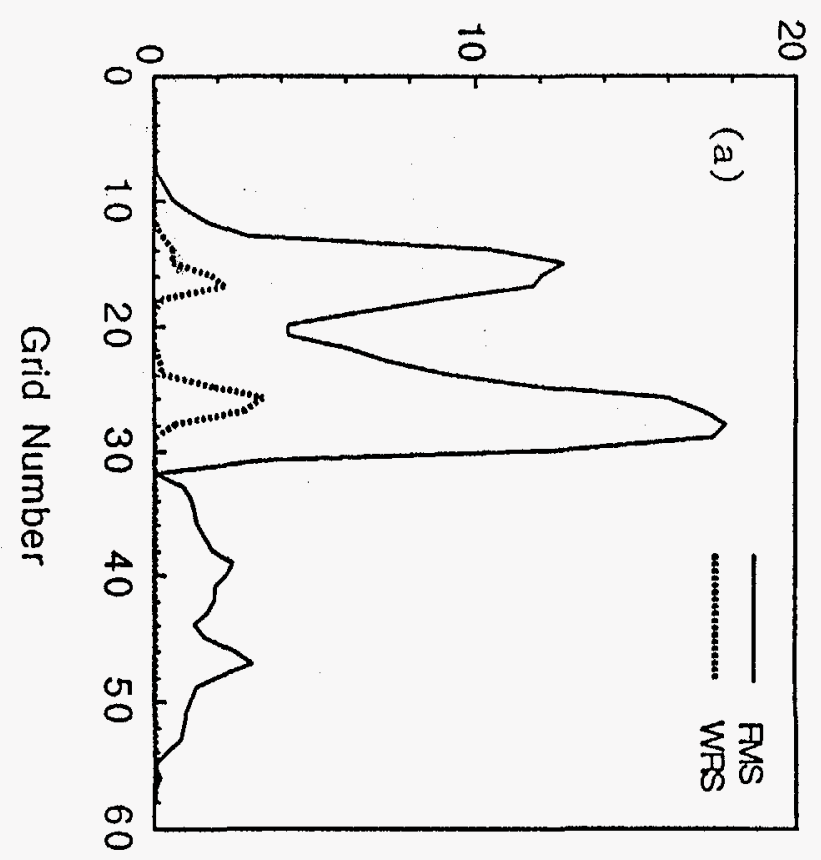

